\title{
ANÁLISE DOS LAÇOS E REDES DE SOCIABILIDADE ENTRE OS PROFESSORES DA ESCOLA TÉCNICA DE COMÉRCIO DO COLÉGIO FARROUPILHA DE PORTO ALEGRE/RS
}

\author{
Eduardo Cristiano Hass da Silva ${ }^{1}$ \\ lattes.cnpq.br/1989339699277505
}

\begin{abstract}
Resumo: Este artigo apresenta parte dos resultados da pesquisa de mestrado desenvolvida pelo autor nos anos de 2015 a 2017, na qual analisou os laços de sociabilidade existentes entre os diferentes sujeitos que frequentavam a Escola Técnica Comercial (ETC) do Colégio Farroupilha de Porto Alegre/RS. O objetivo principal desta pesquisa é demonstrar como os professores que compunham o quadro docente desta instituição criaram laços sociais que permitiram a sua perpetuação. As metodologias empregadas consistem na História Oral e na análise de redes de sociabilidade. Os referenciais teóricos empregados perpassam a Nova História Cultural, História da Educação e Cultura Escolar e História das Instituições Escolares. Os resultados demonstram a existência de diferentes formas de criação e manutenção de laços que aglutinam e moldam os sujeitos que compõem a escola.
\end{abstract}

Palavras-chave: Laços de sociabilidade; Laços entre professores; História da Educação; Ensino Técnico Comercial; História Oral.

\section{ANALYSIS OF THE TIES AND SOCIABILITY NETWORKS BETWEEN THE TEACHERS OF ESCOLA TÉCNICA DE COMÉRCIO DO COLÉGIO FARROUPILHA DE PORTO ALEGRE/RS}

\begin{abstract}
This paper presents part of the results of a master's research developed by the author between 2015 and 2017, which analyzed the social ties existing among the different subjects who attended the Escola Técnica Comercial (ETC) of Colégio Farroupilha from Porto Alegre-RS. The central aim of this research is to demonstrate how the teachers who had become members of the institution's teaching staff created social ties that allowed its perpetuation. The applied methodologies were Oral History and the analysis of sociability networks. The theoretical references used permeate the New Cultural History, History of Education and School Culture and History of School Institutions. The results show the existence of different forms of creation and maintenance of ties that agglutinate and shape the subjects that make up the school.
\end{abstract}

\footnotetext{
${ }^{1}$ Doutorando em Educação pela Universidade do Vale do Rio dos Sinos (Brasil). Contato: eduardo.cristiano@acad.pucrs.br.
} 
Keywords: Sociability ties; Ties among teaches; History of Education; Commercial Technical Education; Oral History.

\section{Introdução}

De 2015 a 2017 realizei o curso de mestrado em História, cujo resultado foi a dissertação intitulada "A gênese de um espaço profissional: a Escola Técnica de Comércio do Colégio Farroupilha de Porto Alegre/RS (1950-1983)"2. A pesquisa teve como temática as carreiras e redes de sociabilidade dos professores que atuaram na Escola Técnica de Comércio (ETC) do Colégio Farroupilha3 entre os anos de 1950 e 1972, tentando entender como os mesmos influenciaram na formação dos técnicos contabilistas da instituição. O objetivo principal da pesquisa consistiu em analisar a formação como Técnico Contabilista no Rio Grande do Sul a partir da atuação dos professores que formaram as primeiras turmas de técnicos em contabilidade no estabelecimento de ensino citado. Os resultados demonstraram a existência de três tipos de laços de sociabilidade: entre professores (laços professores-professores), entre professores e alunos (laços professores-alunos), e também entre professores e proprietários e representantes de empresas locais (laços professores-terceiros). Considerando os estudos anteriores ${ }^{4}$, este trabalho possui dois objetivos: demonstrar como os professores que compunham o quadro docente da instituição estudada criaram laços sociais que permitiram a sua perpetuação (através da análise dos laços de sociabilidade professoresprofessores), retomando e ampliando os resultados atingidos durante a pesquisa de mestrado e; apresentar a aplicação da metodologia de redes sociais e identificação de laços de sociabilidade em pesquisas de História da Educação.

\footnotetext{
2 Para saber mais sobre a pesquisa, ver o texto completo: SILVA, 2017.

3 A ETC do Colégio Farroupilha foi uma instituição que existiu em Porto Alegre/RS, entre os anos de 1950-1983, oferecendo o curso técnico comercial. Um panorama histórico da escola será abordado ao longo do texto.

4 Ver em Silva (2017) o estudo específico sobre os laços de sociabilidade entre os professores e alunos e entre professores e sujeitos externos à instituição.
} 


\section{História da Educação e Cultura Escolar: uma área fronteiriça que desfaz as fronteiras}

Assim, temos que ter como premissa profissional a construção de um sentido crítico e de uma atitude analítica interdisciplinar do campo e das várias situações sócio-educacionais. (BASTOS, 2016, p. 53).

Maria Stephanou e Maria Helena Camara Bastos (2005) caracterizam a História da Educação como uma disciplina fronteiriça entre a História e a Educação, marcada pelo seu aspecto interdisciplinar e multifacetado. Ao propor uma reflexão sobre o que é a História da Educação hoje, Bastos (2016) ainda chama a atenção para a necessidade de um sentido crítico e de uma atitude analítica interdisciplinar para esta área do saber. Detendo-se nos principais enfoques teóricos da disciplina, a autora salienta a importância dos estudos situados dentro de uma concepção dialética e dentro das novas tendências historiográficas.

Ao falar sobre as novas tendências historiográficas, Bastos (2016) retoma os estudos de Fonseca (2008), destacando a relação da História da Educação com a Nova História Cultural. Para a autora, este encontro é o local onde se acabam as fronteiras entre História da Educação e História Cultural, uma vez que a primeira vale-se dos procedimentos metodológicos, conceitos e referenciais da segunda. É justamente neste ponto de encontro onde as fronteiras são desfeitas que este estudo afirma-se teórica e metodologicamente.

Segundo Peter Burke (2005), a História Cultural redescoberta na década de 19705 já vinha sendo praticada pelos historiadores pelo menos há mais de 200 anos, possuindo particularidades de acordo com as dife-

\footnotetext{
5 Na obra, o autor propõe explicar "não apenas a redescoberta, mas também o que é a história cultural, ou melhor, o que os historiadores culturais fazem" (BURKE, 2005, p. 7), dedicando-se às diferenças, debates e conflitos, assim como aos interesses e tradições compartilhadas. Segundo o autor, a História Cultural foi "redescoberta", passou por um processo de transformação na França dos anos 1970, uma vez que os Estudos Culturais despertavam a atenção de muitos pesquisadores.
} 
rentes tradições às quais estivera inserida: tradição francesa, germânica, holandesa, norte-americana e inglesa. De acordo com o autor, a tradição francesa recebeu contribuições importantes a partir dos historiadores associados à Revista dos Annales, em especial de March Bloch e Lucien Febvre, Fernand Braudel, Jacques Legoff, Emmanuel Le Roy Laudurie e Alain Corbin.

Entre as décadas 1960 e 1990, a História Cultural é guinada em direção à Antropologia, fenômeno no qual os historiadores tomam emprestados diferentes termos e conceitos dos antropólogos, permitindo uma espécie de "Antropologia histórica ou história antropológica". Essa nova configuração da História Cultural permitiu apresentar explicações culturais para fenômenos até então vistos apenas como políticos ou econômicos, ampliando os estudos a partir da ideia de cultura. No final da década de 1980 entra em uso a expressão "Nova História Cultural", cuja palavra "nova" serve para distinguir esta tendência da nouvelle historie francesa da década de 1970, e a palavra "cultural" serve para distingui-la da história intelectual e da história social. A Nova História Cultural caracteriza-se por um alargamento dos temas investigados, permitindo estudos da história das práticas, história da leitura, das representações, da memória, dos alimentos, do vestuário, da habitação, do corpo, etc.

É a partir deste alargamento possibilitado pela Nova História Cultural que se torna possível investigar a história dos técnicos contábeis de Porto Alegre e no Rio Grande do Sul a partir de uma instituição específica, bem como os laços de sociabilidade dos professores desta instituição, pois como afirma Chartier (2002, p. 14), dentre os novos objetos das questões históricas destacam-se "os sistemas de parentesco e as relações familiares, os rituais, as formas de sociabilidade, as modalidades de funcionamento escolar, etc.”.

Utilizando-se dos pressupostos da Nova História Cultural, com forte influência da tradição francesa dos Annales, uma das áreas de pesquisa que emerge, de acordo com Stephanou e Bastos (2005) é a História da Educação e da Cultura Escolar, que permite uma vasta possibilidade de objetos e temáticas a serem investigadas. Sendo assim, esse estudo se in- 
sere dentro da história das instituições de ensino, articulado às formas de sociabilidade elencadas por Chartier (2002).

Ao falar dos estudos realizados em história das instituições escolares, Nosella e Buffa (2009) afirmam que, a partir dos anos 1990, é notável a ampliação de linhas teóricas e de fontes de pesquisa, permitindo que os estudos privilegiem diferentes temas. A diversidade de temas relacionados à História da Educação e das Instituições Escolares permite a abordagem do conceito de cultura escolar. De acordo com Dominique Julia (2001, p. 10), a cultura escolar deve ser estudada em paralelo às relações conflituosas ou pacíficas com a história e as culturas que lhe são contemporâneas. Segundo o autor, o termo designa "um conjunto de normas que definem conhecimentos a ensinar e condutas a inculcar, e um conjunto de práticas que permitem a transmissão desses conhecimentos e a incorporação desses comportamentos".

Após apresentados os pressupostos teóricos nos quais esse trabalho se insere, chega o momento de analisar o estabelecimento de ensino estudado, atentando para sua fundação, corpo discente e docente e, finalmente, os laços e redes de sociabilidade entre estes últimos.

\section{A Escola Técnica de Comércio do Colégio Farroupilha de Porto Alegre/RS (1950-1983)6}

Investigar o processo de formação desta instituição mostrou-se um verdadeiro trabalho de procura, coleta e análise de indícios e rastros deixados na história. De acordo com Guinzburg (1989), a história é uma ciência indiciária, na qual cabe ao historiador procurar pelos registros do passado, e a partir deles, assim como a um tapete, tecer as relações entre as fontes encontradas e os princípios teóricos adotados. O primeiro indício referente à história da ETC surgiu a partir da imersão na pesquisa re-

\footnotetext{
${ }^{6}$ A ETC Farroupilha funcionou como parte do Colégio Farroupilha de Porto Alegre, escola mantida pela Associação Beneficente e Educacional (ABE), entidade filantrópica que surgiu no ano de 1858, com o nome de Deutscher Hilfsverein, que significa Sociedade Beneficente Alemã. Para saber mais sobre, ver Jacques (2013).
} 
alizada no Memorial do Colégio Farroupilha de Porto Alegre7. Na busca por informações referentes ao curso comercial, depare-se com um "Demonstrativo da Receita e Despesa da Associação Beneficente e Educacional de 1858”. Em meio ao lamento pela impossibilidade de abertura de um curso colegial complementar ou ginasial na escola, surge a felicitação pela possibilidade de criação de um curso noturno:

Mas, em compensação, transmito aos srs. Associados a boa nova de que, por iniciativa do nosso companheiro do Conselho Escolar, dr. Sven Schulze, se cogita da instalação de um curso técnico comercial de contabilidade, à noite. Os estudos em torno da viabilidade de abertura deste curso estão em andamento,[...] (ABE, 1949, p. 3).

De acordo com o documento, em 7 de abril de 1949 já se cogitava a abertura de um curso técnico comercial em contabilidade, que funcionaria à noite, sendo sua idealização atribuída a um dos membros do Conselho Escolar, Sven Robert Schulze. A segunda evidência que trata da criação da ETC foi localizada no livro "Do Deutscher Hilfsverein ao Colégio Farroupilha (1858/1974)”, de Leandro Telles, que conta a história do colégio. Ao falar sobre os acontecidos na instituição durante o ano de 1949, o autor cita:

Em 10 de novembro a diretoria elege o diretor da Escola Técnica de Comércio Farroupilha, o Dr. Sven Robert Schulze, que fora o propugnador da ideia, que ora se concretizava. O Dr. Sven Robert Schulze é bacharel em Ciências Políticas e Econômicas e Perito Contador. A nova escola passaria a funcionar a partir de 1950 (TELLES, 1974, p. 150).

As informações apresentadas por Telles conferem com as disponíveis no "Demonstrativo da Receita e Despesa da Associação Beneficente e Educacional de 1858", do ano de 1949. Dessa maneira, pode-se afirmar que embora oficialmente criada em 1950, a ETC Farroupilha foi gestada desde abril de 1949, tendo seu diretor eleito em novembro do mesmo

\footnotetext{
7 O "Deutscher Hilfsverein ao Colégio Farroupilha" é um espaço memorialístico inaugurado em 2002. De acordo com Jacques e Grimaldi (2013), o espaço surgiu da necessidade de preservar e divulgar a história da escola e de sua mantenedora, guardando diversos documentos.
} 
ano. Além disso, observa-se que o cargo de diretor é ocupado pelo membro do Conselho Escolar a quem se atribui a ideia de criação do curso comercial.

Sendo o curso técnico do Colégio Farroupilha fundado em 1950, o mesmo era regido pelo decreto lei $\mathrm{n}^{0} 6$. 141, de dezembro de 1943. Intitulada Lei Orgânica do Ensino Comercial, assinada por Gustavo Capanema, decretava sobre a organização do Ensino Comercial, estipulando dentre outras normas, a fiscalização prévia das escolas que ofereceriam o curso. Essa designação era cumprida a partir de uma visita prévia, na qual o Inspetor Federal produzia um relatório, aprovando ou não a abertura do curso técnico.

A partir do Relatório de Verificação Prévia, dos Relatórios de Verificação Geral e de convites de formaturas, utilizando-se da metodologia da prosopografia, elaborei o perfil coletivo dos alunos formados pela instituição ao longo de sua existência (SILVA, 2017). Entre os anos 1950$1982^{8}$, a ETC Farroupilha formou um total de 853 alunos, sendo 565 do sexo masculino e 288 do sexo feminino. Destes alunos, a maioria era composta por brasileiros (826), dos quais, encontra-se naturalidade de Minas Gerais (3), Pará (2), Paraná (5), Pernambuco (1), Piauí (1), Rio de Janeiro (4), Rio Grande do Sul (776), Santa Catarina (28) e São Paulo (6). Ao analisar as famílias das quais provinham os alunos, destaco a presença de membros de famílias de relativo prestígio social na capital gaúcha, como os irmãos Jorge e Frederido Gerdau.

Além disso, a pesquisa demonstrou que a ETC Farroupilha possui dois momentos históricos bastante definidos quando vista a partir da constituição do seu corpo docente. O primeiro momento vai da fundação da instituição em 1950 até o ano de 1972, no qual a escola muda-se do Centro de Porto Alegre para o bairro Três Figueiras e quando começam a serem implantadas as modificações impostas pela Reforma do Ensino, estipulada pelo decreto-lei $n^{0} 5.692$, que fez do técnico em contabilidade

\footnotetext{
8 Oficialmente, a ETC Farroupilha é desativada em 1983. No entanto, a última turma de formandos foi no ano anterior, sendo os primeiros meses de 1983 utilizados para a transferência dos alunos que ainda frequentavam a instituição e para a burocracia de desativação da escola.
} 
uma habilitação do ensino do segundo nível. O período posterior estende-se de 1972 até 1983, ano em que a escola é desativada. O decreto mencionado provocou grande mudança no perfil profissional dos professores que compunham a escola, pois até então, em paralelo a atividade de docentes, exerciam profissões referentes às disciplinas que ministravam. A partir de 1972, os professores que passam a compor o quadro docente da escola são predominantemente licenciados, não exercendo mais outras profissões.

Neste estudo, proponho analisar as carreiras e laços de sociabilidade dos professores que ingressaram na escola até o ano de 1972. O levantamento dos nomes resultou em 27 sujeitos. De forma geral, as principais informações acerca dos docentes podem ser observadas no quadro abaixo:

Quadro 1 - Professores da ETC Farroupilha contratados entre 1950-1972, por ordem alfabética. Fonte: SILVA (2017).

\begin{tabular}{|l|c|l|l|}
\hline \multicolumn{1}{|c|}{ Nome } & Sexo & \multicolumn{1}{|c|}{ Naturalidade } & Nacionalidade \\
\hline Altidor Martins da Silva & M & São Leopoldo & Brasileira \\
\hline Antônio Coelho Nunes & M & Porto Alegre & Brasileira \\
\hline Carlos Silveira Hessel & M & Porto Alegre & Brasileira \\
\hline Casimiro Medeiros Jacobs & M & $\begin{array}{l}\text { Conceição do Arroio, } \\
\text { Osório }\end{array}$ & Brasileira \\
\hline Cláudio Walter Matto Ferreira da Silva & M & Encruzilhada do Sul & Brasileira \\
\hline Débora Nascimento Sette & F & Recife - Pernambuco & Brasileira \\
\hline Edwin Bischoff & M & Cachoeira do Sul & Brasileira \\
\hline Elenir Brum Reck & M & Tupanciretã & Brasileira \\
\hline Ely Fumagalli Horta & M & Júlio de Castilhos & Brasileira \\
\hline Guida Reinilhdis Braun & F & Estrela & Brasileira \\
\hline Hans Joachim Walter Sille & M & Pelotas & Brasileira \\
\hline Horst Beck & M & Porto Alegre & Brasileira \\
\hline João Pedro dos Santos & M & Taquara & Brasileira \\
\hline Lélis Souza de Souza & F & Lavras do Sul & Brasileira \\
\hline Maria Aracy Karan Meneses & F & Santa Cruz do Sul & Brasileira \\
\hline
\end{tabular}




\begin{tabular}{|l|c|l|l|} 
Nagib Leitune Kalil & M & Tapes & Brasileira \\
\hline Namir Viana Lautert & M & Estrela & Brasileira \\
\hline Nei Burmeister & M & Porto Alegre & Brasileira \\
\hline Pedro Bolivar Marzullo de Oliveira & M & Alegrete & Brasileira \\
\hline Plínio Lúcio Frantz & M & Santa Cruz do Sul & Brasileira \\
\hline Rodolpho George & M & Porto Alegre & Brasileira \\
\hline Ruby Felisbino Medeiros & M & Caxias do Sul & Brasileira \\
\hline Sven Roberto Schulze & M & Porto Alegre & Brasileira \\
\hline Walter Egon Poisl & M & Porto Alegre & Brasileira \\
\hline Walter Frederico Matschulat & M & Santa Cruz do Sul & Brasileira \\
\hline Walter Jacob Striebel & M & Alemanha & $\begin{array}{l}\text { Brasileira } \\
\text { (naturalização) }\end{array}$ \\
\hline Walter Kley & M & Porto Alegre & Brasileira \\
\hline
\end{tabular}

Uma análise geral do quadro permite algumas observações. Destaca-se a predominância de docentes homens (23) em detrimento de mulheres (4) 9 . Além disso, observa-se que dos 27 professores, 26 eram brasileiros, sendo apenas um deles nascido na Alemanha, mas naturalizado brasileiro. Uma análise detalhada dos sobrenomes desses professores pode mostrar que, embora nascidos no Brasil, tenham origem germânica. Quanto à naturalidade dos 26 professores brasileiros, 25 são gaúchos, sendo a maioria nascida em Porto Alegre (8). Como esses docentes eram contratados? Quais os laços sociais existentes entre eles? Como era feita a manutenção desses laços? Qual a importância da atuação destes professores na existência e perpetuação da ETC Farroupilha? São esses questionamentos que direcionarão a última parte desta pesquisa.

\footnotetext{
9 O número de professoras na escola não pode ser visto como fruto de uma "ausência" feminina, mas pelo contrário, como "presença”. Em um estudo específico sobre a trajetória profissional das mulheres, Louro (2000) mostrou a tendência em destiná-las a profissões como a docência e a enfermagem. Sendo assim, pensar quatro mulheres que exerciam profissões ligadas ao comércio (além da docência na instituição), mostra que essas mulheres estavam, de alguma forma, rompendo com os lugares que a sociedade tendia a destinar-lhes.
} 


\section{Laços e redes de sociabilidade entre os professores da ETC Farroupilha}

De acordo com Barnes, laço é a ligação existente entre sujeitos, podendo configurar-se como uma ligação social, de amizade ou parentesco. Enquanto isso, a rede social é o instrumento analítico utilizado por muitos antropólogos que estudam política local para identificar a presença desses laços. Para o autor, assim como no plano macro (o plano da política nacional), existem relações que podem ser observadas no plano micro (o plano do local):

É fácil perceber que processos similares àqueles encontrados no nível político nacional - como os de alianças, desafio e compromisso, testes de força e distribuição de recompensas - operam dentro da região, do distrito, e da aldeia bem como dentro dos clãs, companhias, igrejas e outros grupos não territoriais; mesmo dentro da família estão correndo processos similares (BARNES, 1987, p. 159).

Conforme o autor, os processos de aliança, desafio e compromisso presentes no nível político nacional podem ser identificados também dentro de espaços locais como a região, distrito ou aldeia, ou até mesmo de instituições como companhias, igrejas ou família. Sendo assim, justifica-se a aplicabilidade deste conceito para uma instituição escolar, no caso, a ETC Farroupilha. Segundo Barnes, esses processos políticos de nível local ocorrem dentro de instituições que preenchem muitas funções que não são necessariamente políticas. A solução para identificar esses processos seria então adotar a perspectiva de uma "política escolar", que permite encontrar os processos a partir dos quais os grupos de professores da ETC tentavam mobilizar apoio para seus objetivos: "devemos, [...] adotar a perspectiva de política que está implícita em expressões como política acadêmica, política do esporte, política da igreja, etc.” (BARNES, 1987, p. 160).

Os laços de amizade entre os professores da ETC Farroupilha parecem estar presentes desde sua origem. A fundação da escola e os meca- 
nismos de seleção de professores envolvem diretamente o professor que a idealizou, o já nomeado Sven Roberto Schulze. Como teria ocorrido esse processo de seleção? Algum concurso? Indicações? Esses questionamentos puderem ser respondidos a partir de memórias produzidas com a metodologia da história oral10. Segundo Paul Ricoeur (2007), memória e história são diferentes, existindo uma passagem da primeira para a segunda, passagem na qual os testemunhos são estruturas fundamentais. Sendo assim, não tomo as memórias dos sujeitos entrevistados como história, mas faço-as passar pelas três fases da operação historiográfica apresentadas pelo autor: fase documental (da declaração das testemunhas oculares à constituição dos arquivos), fase explicativa/compreensiva (questionamento dos documentos produzidos) e fase representativa (colocação em forma literária ou escrita do discurso). O nome dos entrevistados e sua relação com a ETC podem ser observados no quadro:

Quadro 2 - Relação de entrevistados, elaborado pelo autor.

\begin{tabular}{|l|l|c|c|}
\hline \multicolumn{1}{|c|}{ Nome } & \multicolumn{1}{|c|}{ Relação com a ETC } & \multicolumn{1}{c|}{ Tempo } & Páginas \\
\hline $\begin{array}{l}\text { SILLE, Hans } \\
\text { Joachim Walter }\end{array}$ & Ex-professor da ETC & 2h 34min 22s & 44 \\
\hline KLEY, Ivam & $\begin{array}{l}\text { Filho do professor } \\
\text { Walter Kley }\end{array}$ & 1h 16min 5Os & 41 \\
\hline SCHULTZ, Ingrid & $\begin{array}{l}\text { Filha do professor } \\
\text { Sven Schultz }\end{array}$ & 1h 17min 58s & 21 \\
\hline POISL, Walter & Ex-professor da ETC & 1h 31min 54s & 21 \\
\hline
\end{tabular}

${ }^{10}$ A realização desta pesquisa contou com a realização de quatro entrevistas entendidas a partir da metodologia de história oral. As técnicas foram empregadas a partir dos pressupostos de Verena Alberti (2004). Todos os entrevistados assinaram o Termo de Livre Esclarecimento, autorizando a utilização de seus nomes e de suas memórias. 
Ao ser questionado sobre a ideia de fundação da instituição, Ivam Kley (2016, p. 7) afirma: "Isso aí é uma ideia que eles tiveram, essa turminha dele, do Schultz". Como pode-se observar nas palavras de Ivam Kley, existiria uma "turminha", termo utilizado para designar o grupo de professores articulados em torno do fundador da ETC, Sven Schultz. Essa afirmação é o primeiro indício da forma de como teria ocorrido o processo de seleção dos profissionais que iriam compor o corpo docente. Esse fragmento pode ser analisado em paralelo às memórias de Ingrid Schultz (2016, p. 3), que ao contar sobre o processo de formação do corpo docente da escola, destaca:

[...] o pai achou por bem movimentar para criar uma escola desse tipo. Então ele contatou profissionais, já que ele tinha muitos relacionamentos, de diferentes áreas que compunham aquelas disciplinas necessárias para a formação de um contador. E os conhecidos convidaram outros. Então eles formaram uma equipe, eles eram muito amigos e conheciam-se mutuamente [...].

A fala de Ingrid Schultz reforça a ideia apresentada por Ivam Kley da existência de uma "turminha" aglutinada em torno do professor Schultz. Como pode-se observar na fala da entrevistada, após concretização da criação da Escola de Comércio, seu pai foi o responsável por formar o corpo docente da instituição, chamando para atuarem nele profissionais com formação referente às disciplinas que seriam oferecidas. A particularidade da fala de Ingrid está na forma como esses profissionais foram escolhidos. De acordo com ela, eles eram conhecidos de seu pai. Além disso, a fala da entrevistada pode ser analisada a partir da metodologia de redes. Como ela afirma, seu pai chamou conhecidos, que por sua vez, chamaram outros conhecidos, permitindo a formação de um grupo, no qual os professores "eram muito amigos e conheciam-se mutuamente". A partir de Barnes (1987), pode-se afirmar aqui a existência de um laço social, identificado como de amizade.

A contratação do professor Walter Sille também pode ser compreendida dentro desta rede social de amizades, embora ele não conhecesse o professor Sven. De acordo com Sille, ele não estivera presente na fun- 
dação da ETC, pois já havia uma professora que lecionaria Inglês. No entanto, não podendo assumir a vaga, a própria professora o contatou. Ao falar da fundação da escola, afirma:

Na fundação propriamente dita, já tinham uma professora de inglês, que inclusive havia feito curso comigo, a Mercedez Marchand. Ela já tinha pego aquele lugar. No entanto, quando viu que era de noite e que era mais o inglês comercial, ela me telefonou (na verdade, não lembro como naquela época a gente se comunicava): Sille, vai lá, que isso aqui é para ti, não é para mim (SILLE, 2015, p.17).

As memórias de Sille coincidem com as afirmações de Ingrid de que o professor Sven contatou profissionais conhecidos, que por sua vez, contataram outros conhecidos. Considerando que Mercedez Marchand não assumiu, e que os professores a lecionarem no primeiro ano da ETC (1950) foram Sven Schulze (Mecanografia), Walter Kley (Física e Química e Contabilidade Geral), Ruby Felisbino Medeiros (Português) e Walter Sille (Inglês), pode-se traçar os laços desses primeiros docentes:

Imagem 1 - Organograma dos laços de amizade entre os professores convidados para atuar durante o primeiro ano (1950) da ETC Farroupilha, elaborado pelo autor.

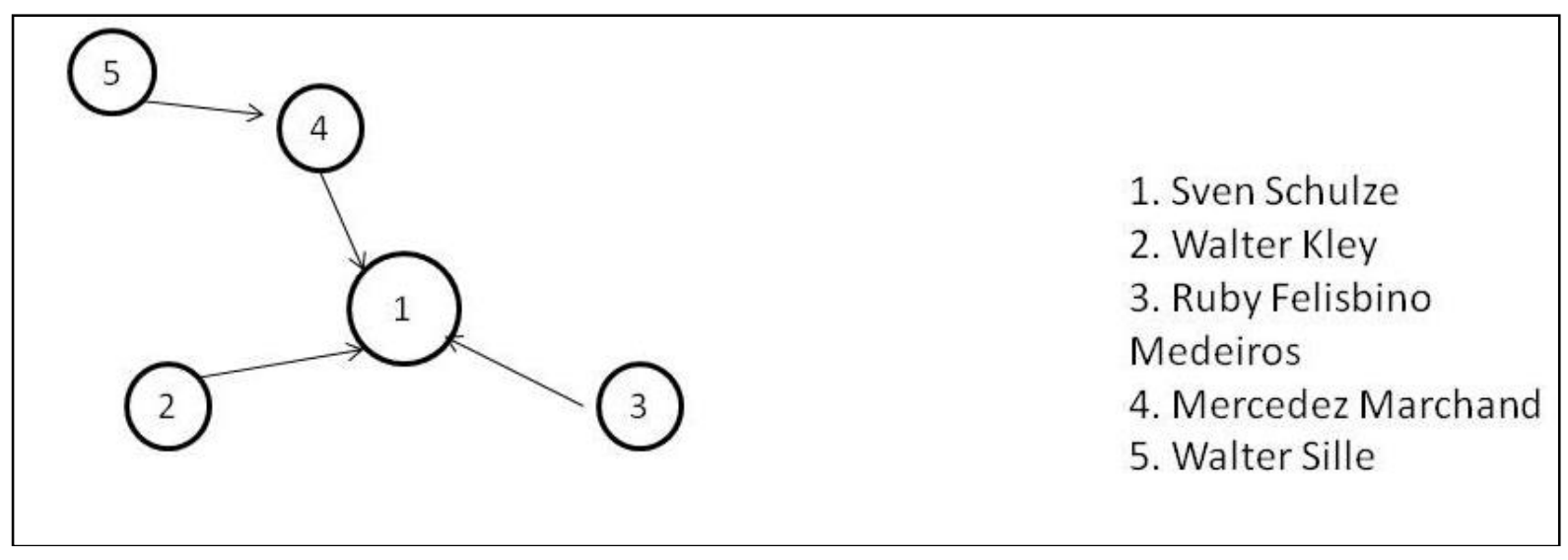

A análise do organograma permite algumas afirmações sobre os professores convidados para atuarem na ETC Farroupilha em 1950. Inicialmente, destaca-se que o centro da estrutura criada é o professor Sven Schulze, a quem todos os outros estão direta (Walter Kley, Ruby Felisbi- 
no Medeiros e Mercedez Marchand) ou indiretamente (Walter Sille) ligados, a partir de laços sociais de amizade. O professor Walter Sille é o único indivíduo indiretamente ligado, o que se justifica por ter sido convidado a atuar na instituição pela professora que não pode assumir (Mercedez Marchand).

Mas quem foi Sven Schulze, a quem se atribui a criação e organização da ETC, além da seleção do seu corpo decente? Quem é esse professor que foi o primeiro diretor da instituição? Quem é o sujeito que ocupa o lugar central nos laços formados entre os professores? As respostas a estas inquietações podem sem dadas a partir da biografia do professor:

Sven Roberto Schulze nasceu no dia 15/12/1910, na cidade de Porto Alegre, RS. Filho de Bernhard Oscar Schulze e Herminia Ida Brandt Schulze. Formado como perito-contador pela Faculdade de Ciências Políticas e Econômicas de Porto Alegre (1936) e Bacharel em Ciências Econômicas pela mesma. A ele é atribuía a ideia de criação da ETC do Colégio Farroupilha. No ano de 1949, no qual teria iniciado a movimentação para criação da instituição, era conselheiro da Associação Beneficente e Educacional (ABE), mantenedora do Colégio Farroupilha. Foi o responsável por organizar o curso comercial, bem como selecionar os professores que iriam compor o quadro docente da instituição. Além disso, foi o primeiro diretor da ETC, exercendo esse cargo entre 1950 e 1953 e, posteriormente, assume a vicedireção. Atuou também como professor, entre os anos de 1950 e 1969, totalizando 19 anos como docente. As disciplinas que lecionava estavam associadas às máquinas utilizadas pelos contadores, pois além de atuar como professor era dono de uma microempresa e uma oficina mecanográfica. Pai de cinco filhos, quais três formaram-se na ETC Farroupilha, nos anos de 1967, 1968 e 1970. Sua filha, Ingrid Schulze, atuou como professora do Colégio Farroupilha. (SILVA, 2017)

A partir da biografia de Sven Schulze pode-se observar que quando propôs a criação da ETC Farroupilha, era conselheiro da ABE, mantenedora do Colégio Farroupilha, função considerada de prestígio até hoje. Após criado o curso comercial, Sven foi o primeiro diretor da instituição, exercendo essa função entre os anos de 1950 e 1953 e, assumindo, posteriormente, a vice-direção. Além de idealizador, diretor e vice-diretor, Sven foi também professor da ETC durante 19 anos, lecionando discipli- 
nas ligadas à utilização das máquinas contábeis. Dos seus cinco filhos, três cursaram o curso comercial, o que evidencia que além dos laços de amizade, Sven possuía também dentro da instituição laços de familiaridade.

Depois de apresentados os laços de sociabilidade existentes entre os professores, surge um novo questionamento: como era feita a manutenção destes laços? Mais uma vez as respostas ao questionamento podem ser dadas a partir das memórias produzidas com as entrevistas, que evidenciam a constante realização de reuniões, que serviam de encontros de avaliação e aproximação. Ao falar sobre as relações entre os professores, o professor Walter Poisl (2016, p. 9) afirma:

Nós éramos uma grande comunidade, de muitos amigos. Até o Inspetor Federal fazia parte da nossa comunidade. Ele era também muito amigo. Ele chamava-se Gobbato. [...] Fazíamos reuniões, toda a semana não, mas duas vezes por mês, fazíamos uma reunião para ver como ia o curso.

Como afirma o professor, o grupo de professores formava uma grande comunidade de amigos, o que incluía inclusive o Inspetor Federal, Milton Gobbato. Essa fala evidencia a presença e manutenção dos laços para além do espaço escolar, incluindo também o indivíduo responsável pela fiscalização do Curso Comercial. De acordo com Poisl, os professores costumavam fazer reuniões duas vezes por mês, tendo a intenção de avaliar o andamento do curso. As reuniões são lembradas também pelo professor Sille, que ao falar das relações dos professores destaca que eram "belíssimas, a tal ponto de que para toda e qualquer reunião, nós éramos sempre em casais. Todos os professores se reuniam para uma reunião e vinha a esposa conosco" (SILLE, 2015, p. 11). Como se observa com a fala de Sille, era comum a presença das esposas nessas reuniões, o que mostra o caráter desses encontros para além da avaliação do trabalho dos professores, tinha também a função de estreitamento dos laços entre as famílias. Na continuidade das memórias de Sille, esses encontros são melhor explicados: 
[...] qualquer festinha, festinha não necessariamente de coquetel e etc., mas de nascimento de uma criança, por exemplo, alguém tinha que levar flores ou tinha que fazer uma visita. Não é obrigação nesse sentido negativo. As mulheres iam visitar-se. Até hoje se comunicam. Formou-se uma, um, um time, não é palavra. Um grupo de pessoas que simpatizaram mutuamente. (SILLE, 2015, p. 19).

As memórias do professor evidenciam diferentes mecanismos de manutenção dos laços de sociabilidade. Percebe-se as visitas feitas em momentos específicos, como em nascimentos, visitas nas quais as esposas desses professores exerciam a função de aproximar e estreitar laços. De acordo com o professor, esses laços estenderam-se até os dias atuais, permitindo a formação de "um grupo de pessoas que simpatizaram mutuamente”. A presença das famílias nos encontros é lembrada também por Ingrid Schulze, que, enquanto filha do professor Sven Schulze, participava com o pai, mãe e irmãos dessas reuniões. Ao falar dos encontros dos professores, Ingrid (SCHULZE, 2016, p. 7-8) destaca:

Eles faziam muitos encontros. Havia um encontro com as famílias, com as esposas, com os filhos, todo ano tinha encontro. Confraternizavam bastante. Fizeram uma equipe bem unida assim, bem amiga. Tanto que muitos professores permaneceram por muitos anos. Alguns entravam e saiam, mas um núcleo permaneceu praticamente todo o tempo.

As memórias de Ingrid permitem algumas observações interessantes a respeito da manutenção dos laços entre os professores. Inicialmente, a entrevistada destaca a realização de muitos encontros, encontros esses nos quais estavam presentes além dos professores, suas esposas e filhos. Além da realização dos encontros, as memórias de Ingrid revelam o quanto os laços entre os professores eram importantes, sendo que "alguns entravam e saiam, mas um núcleo permaneceu praticamente todo o tempo" (SCHULZE, 2016, p. 8). Essa afirmação de Ingrid pode ser reforçada quando analisamos o tempo de atuação de cada professor na ETC Farroupilha: 
Quadro 3 - Tempo de atuação dos professores da ETC

Farroupilha com ingresso entre 1950-1972. Fonte: SILVA (2017).

\begin{tabular}{|l|c|c|}
\hline \multicolumn{1}{|c|}{ Nome } & Período & Tempo \\
\hline Débora Nascimento Sette & $1972-1972$ & 1 ano \\
\hline Guida Reinilhdis Braun & $1972-1972$ & 1 ano \\
\hline Nagib Leitune Kalil & $1956-1957$ & 1 ano \\
\hline Carlos Silveira Hessel & $1967-1968$ & 1 ano \\
\hline Antônio Coelho Nunes & $1970-1972$ & 2 anos \\
\hline Altidor Martins da Silva & $1970-1972$ & 2 anos \\
\hline Elenir Brum Reck & $1959-1962$ & 3 anos \\
\hline Walter Frederico Matschulat & $1956-1961$ & 5 anos \\
\hline Maria Aracy Karan Meneses & $1971-1976$ & 5 anos \\
\hline Ruby Felisbino Medeiros & $1950-1957$ & 7 anos \\
\hline Horst Beck & $1956-1965$ & 9 anos \\
\hline Plínio Lúcio Frantz & $1970-1981$ & 11 anos \\
\hline Pedro Bolivar Marzullo de Oliveira & $1971-1981$ & 10 anos \\
\hline Rodolpho George & $1956-1971$ & 15 anos \\
\hline Casimiro Medeiros Jacobs & $1962-1978$ & 16 anos \\
\hline Walter Egon Poisl & $1953-1969$ & 16 anos \\
\hline Edwin Bischoff & $1956-1972$ & 16 anos \\
\hline João Pedro dos Santos & $1953-1969$ & 16 anos \\
\hline Cláudio Walter Matto Ferreira da Silva & $1956-1973$ & 17 anos \\
\hline Nei Burmeister & $1964-1981$ & 17 anos \\
\hline Sven Roberto Schulze & $1950-1969$ & 19 anos \\
\hline Walter Jacob Striebel & $1950-195-1973$ & 22 anos \\
\hline Walter Kley & 22 anos \\
\hline Hans Joachim Walter Sille & 22 anos \\
\hline Ely Fumagalli Horta & 23 anos \\
\hline Lélis Souza de Souza & anos \\
\hline Namir Viana Lautert & 1972 & anos \\
\hline
\end{tabular}


A análise do quadro corrobora com a afirmação de Ingrid de que, enquanto alguns professores "entravam e saiam" outros permaneceram por muito tempo. Tomando por exemplo os primeiros e últimos professores do quadro, pode-se observar que enquanto Débora Nascimento Sette, Guida Reinilhdis Braun, Nagib Leitune Kalil e Carlos Silveira Hessel permaneceram um ano na ETC, outros professores permaneceram muito tempo, como Walter Jacob Striebel (22 anos), Walter Kley (22 anos), Hans Joachim Walter Sille (22 anos), Ely Fumagalli Horta (23 anos), Lélis Souza de Souza (23 anos) e Namir Viana Lautert (24 anos).

Os elementos aqui analisados demonstram a importância não apenas da existência, mas também da manutenção dos laços de sociabilidade. É notável que parte do corpo docente da instituição manteve-se o mesmo ao longo de sua existência, enquanto outra parte permanecia pouco tempo. A metodologia de redes aqui empregada permite afirmar que o corpo docente permanente era bastante coeso, com fortes laços de ligação. Dessa forma, os professores contratados que não se identificassem com esse grupo, não conseguiam permanecer na rede de professores.

\section{Algumas considerações}

A partir dos pressupostos da História da Educação e Cultura Escolar, utilizando das metodologias da História Oral e a Análise de Redes, apresentei aqui a existência dos laços de sociabilidade existentes entre os professores da ETC Farroupilha, laços que misturam amizade e profissão. Esses laços estiveram presentes desde a criação da instituição, na qual seu idealizador formou um corpo profissional a partir dos seus contatos pessoais.

Além disso, evidenciou-se a importância da manutenção destes laços a partir das reuniões e encontros, bem como da aproximação das famílias. Esses elementos permitiram que parte do corpo docente do curso comercial tenha se perpetuado na escola, enquanto outros, provavelmente aqueles que não se identificaram com esses laços, tenham entrado e 
saído da instituição. O grupo permanente de professores era ligado por fortes laços de amizade, criando uma equipe coesa, capaz de ditar quem permaneceria ou não. Existiriam outros laços de sociabilidade além dos de amizade? Como seria feita a manutenção destes laços? Esses são alguns dos questionamentos que mostram a necessidade de continuação deste estudo, visando aprimorar os resultados até aqui obtidos.

Mais que apresentar resultados específicos sobre o estudo de caso realizado, este artigo mostra a potencialidade da metodologia da análise de redes e de laços sociais em História da Educação. Com esse método, pode-se identificar os sujeitos que perpassam o espaço escolar bem como as relações entre os mesmos, possibilitando diferentes explicações para os mecanismos de seleção, continuação e perpetuação que fazem parte da vida escolar.

\section{Referências}

ALBERTI, V. Ouvir Contar: textos em História Oral. Rio de Janeiro: Editora FGV, 2004.

BARNES, J. A. redes sociais e processo político. In: FELDMAN-BIANCO, B. (org.). A antropologia das sociedades contemporâneas. São Paulo: Global, 1987.

BASTOS, M. H. C. O que é História da Educação hoje? Tempos de Reflexão. Espacio, Tiempo y Educación, 3 (1), 43-59, 2016.

BURKE, P. O que é história cultural? Rio de Janeiro: Jorge Zahar Editor, 2005.

CHARTIER, R. A História Cultural: entre práticas e representações. 2 ed. Rio de Janeiro: Difel, 2002.

GINZBURG, C. Mitos, emblemas, sinais: morfologia a história. São Paulo: Companhia das Letras, 1989.

JACQUES, A. R.; GRIMALDI, L. C. O Memorial do Deutscher Hilfsverein ao Colégio Farroupilha: um espaço de ensino e pesquisa (2002). In: BASTOS, M. H. C. et al. (org.). Do Deutscher Hilfsverein ao Colégio Farroupilha/RS: memórias e histórias (1858-2008). Porto Alegre: EDIPUCRS, 2013, p. 77-91. 
JACQUES, A. R. Associação Beneficente Educacional de 1858 e o Colégio Farroupilha (1886). In: BASTOS, M. H. C. et al. (org.). Do Deutscher Hilfsverein ao Colégio Farroupilha/RS: memórias e histórias (18582008). Porto Alegre: EDIPUCRS, 2013. p. 51- 76.

JULIA, D. A cultura escolar como objeto histórico. Revista Brasileira de História da Educação, n. 1, p. 9-43, 2001.

NOSELLA, P. BUFFA, E. Instituições escolares. Por que e como pesquisar. Campinas: Alínea, 2009.

RICOEUR, P. A memória, a história, o esquecimento. Campinas: Editora da Unicamp, 2007.

SILVA, E. C. H. A gênese de um espaço profissional: a Escola Técnica de Comércio do Colégio Farroupilha de Porto Alegre/RS (1950-1983). Dissertação (Mestrado em História). Pontifícia Universidade Católica do Rio Grande do Sul, Porto Alegre, 2017.

STEPHANOU, M.; BASTOS, M. H. C. História, memória e História da Educação. In: Histórias e memórias da educação no Brasil. v. III - século XX. Petrópolis: Vozes, 2005, p. 416-429.

TELLES, L. S. Do Deutscher Hilfsverein ao Colégio Farroupilha (1858/ 1973). Oficinas Gráficas da Livraria do Globo, Porto Alegre, 1974.

\section{Documentos}

ABE. Resultado Financeiro - Demonstrativo da Receita e Despesa da Associação Beneficente e Educacional de 1858, 1949.

BRASIL, Lei $\mathrm{n}^{\circ}$ 6.141, de 28 de dezembro de 1943.

BRASIL, Lei $\mathrm{n}^{0}$ 5.692, de 11 de agosto de 1971.

RELATÓRIO de Verificação Prévia da Escola Técnica de Comércio Farroupilha. Porto Alegre, RS. Elaborado pelo Inspetor-auxiliar Gastão Loureiro Chaves, 1949.

\section{Entrevistas}

KLEY, I. Entrevista sobre a Escola Técnica Comercial do Colégio Farroupilha de Porto Alegre [28/01/2016]. Entrevistador: Eduardo Cristiano Hass da Silva, 2016.

POISL, W. Entrevista sobre a Escola Técnica Comercial do Colégio Farroupilha de Porto Alegre [16/05/2016]. Entrevistador: Eduardo Cristiano Hass da Silva, 2016. 
SCHULTZ, I. Entrevista sobre a Escola Técnica Comercial do Colégio Farroupilha de Porto Alegre [29/01/2016]. Entrevistador: Eduardo Cristiano Hass da Silva, 2016.

SILLE, H. J. W. Entrevista sobre a Escola Técnica Comercial do Colégio Farroupilha de Porto Alegre [11/12/2015]. Entrevistadores: Eduardo Cristiano Hass da Silva e Lucas Costa Grimaldi, 2015.

Recebido em o8 de fevereiro de 2017. Aprovado em 20 de fevereiro de 2017. 